\title{
FERRO ZERO: UMA NOVA ABORDAGEM PARA O TRATAMENTO DE ÁGUAS CONTAMINADAS COM COMPOSTOS ORGÂNICOS POLUENTES
}

\author{
Wellington S. Pereira e Renato S. Freire* \\ Departamento de Química Fundamental, Instituto de Química, Universidade de São Paulo, CP 26077, 05513-970 São Paulo-SP \\ Recebido em 26/3/04; aceito em 9/6/04; publicado na web em 9/9/04
}

\begin{abstract}
ZERO-VALENT IRON: A NEW APPROACH FOR TREATMENT OF WATERS CONTAMINED WITH ORGANIC POLLUTANTS. Anthropogenic pollution of groundwater and surface water has become a very serious environmental problem around the world. A wide range of toxic pollutants is recalcitrant to the conventional treatment methods, thus there is much interest in the development of more efficient remediation processes. Degradation of organic pollutants by zero-valent iron is one of the most promising approaches for water treatment, mainly because it is of low cost, easy to obtain and effective. After a general introduction to water pollution and current treatments, this work highlights the advances, applications and future trends of water remediation by zero-valent iron. Special attention is given to degradation of organochloride and nitroaromatic compounds, which are commonly found in textile and paper mill effluents.
\end{abstract}

Keywords: environmental chemistry; industrial effluents; new treatment processes.

\section{INTRODUÇÃO}

A água é um dos recursos naturais mais importantes da Terra, sendo imprescindível para a geração e manutenção de todas as formas de vida em nosso planeta. O volume total de água na Terra é estimado em 1,34 bilhões de $\mathrm{km}^{3}$, mas somente $2,7 \%$ deste valor correspondem à água doce, sendo que boa parte desta água encontra-se congelada nos pólos (cerca de três quartos) ou armazenada em depósitos subterrâneos $^{1,2}$. Os lagos, riachos, córregos e rios, que são as principais fontes de água potável, representam em conjunto apenas aproximadamente $0,01 \%$ do suprimento total de água ${ }^{1}$. Devido a problemas de distribuição geográfica irregular e de má conservação da qualidade dos recursos hídricos, em todo o mundo cerca de 1,1 bilhão de pessoas sofrem com a falta de água para as suas necessidades mínimas e 2,4 bilhões não dispõem de programas de tratamento de água ${ }^{1}$. Apesar da porcentagem reduzida de água doce disponível, a água é um dos recursos naturais mais utilizado pelo homem, sendo fundamental em uma ampla gama de atividades, tais como abastecimento público, processos produtivos industriais, agropecuária (responsável por $70 \%$ do consumo da água em nosso país ${ }^{1}$ ), recreação e, infelizmente, como depósito de uma série de resíduos inerentemente produzidos durante as atividades antropogênicas ${ }^{1}$.

O Brasil é considerado um país privilegiado em termos de disponibilidade de recursos hídricos, pois possui cerca de $12 \%$ da água doce disponível no mundo ${ }^{1}$. Até o final do século passado, a água era tida como um recurso abundante e praticamente inesgotável. Infelizmente esta concepção mostrou-se equivocada, pois constantes mudanças geoclimáticas vêm alterando a disponibilidade de água potável; muitas destas mudanças são decorrentes das atividades humanas (desmatamento, emprego indiscriminado de defensivos agrícolas, assoreamento de rios e nascentes, impermeabilização dos solos, poluição da atmosfera, ocupação de mananciais, etc.). Além destes problemas, tem-se ainda uma série de carências quanto ao planejamento urbano (regiões de mananciais encontram-se ocupadas pela população de menor poder aquisitivo dos grandes centros urbanos;

*e-mail: rsfreire@ iq.usp.br há um alto grau de concentração humana em determinadas áreas; etc.) e quanto à racionalização do uso da água (há enormes desperdícios durante sua distribuição e utilização; dependendo da região metropolitana estima-se uma perda entre 40 e $75 \%$ do total de água fornecida à população) $)^{3}$. Não obstante, uma das agressões mais impactantes aos recursos hídricos é a falta de tratamento adequado dos resíduos industriais e domésticos que, constantemente, são despejados nos corpos d'água sem nenhum processo de remediação.

\section{Custo da água $\mathrm{x}$ processos produtivos}

Este panorama mostra que a atual forma de apropriação e gerenciamento dos recursos hídricos não é a mais adequada. A sociedade civil, principalmente por meio de organizações não governamentais (ONGs) e pela mídia, tem pressionado o poder público para tomar medidas que revertam este quadro ${ }^{4}$. Em 1995 foi criado o Ministério do Meio Ambiente, de Recursos Hídricos e da Amazônia Legal e dois anos depois foi sancionada a Lei $n^{\circ} 9.433$ que definiu a Política Nacional de Recursos Hídricos, cuja missão é a de assegurar à atual e às futuras gerações a disponibilidade de água em padrões adequados aos seus mais diversos usos ${ }^{1}$. Para implementar esse gerenciamento, no ano de 2000, foi criada a Agência Nacional das Águas (ANA), encarregada de coordenar a cobrança pelo uso da água.

A nova legislação reconhece os recursos hídricos como bem público, de valor econômico, cuja utilização deve ser controlada e taxada. Esta questão tem gerado muita polêmica e induzido novas posturas nos ramos produtivos, principalmente no industrial. Assim, a preocupação do uso racional da água vem sendo norteada basicamente em função de seu custo, que tende a aumentar devido aos conceitos de consumidor pagador e poluidor pagador, regidos pela legislação ambiental ${ }^{5}$. Além disso, a sociedade ("clientes") tem-se tornado cada vez mais crítica e exigente com relação à qualidade e ao impacto ambiental dos produtos que consome. Isto tem levado as indústrias a buscarem novos processos em suas linhas produtivas, visando satisfazer esta nova demanda ${ }^{4}$. Desta maneira, as questões ambientais vêm sendo agregadas aos negócios, as empresas que se preocupam em minimizar o impacto de seus rejeitos ao meio ambiente têm conseguido agregar valor aos seus produtos; por outro lado, 
aquelas que mantiverem a postura de aumentar seus lucros e compartilhar poluentes tendem a perder competitividade.

Apesar destas novas orientações, as atividades humanas continuam provocando um grande impacto nos ecossistemas aquáticos, sendo que os despejos de efluentes industriais e domésticos constituem a maior fonte antrópica de compostos químicos que são lançados nos corpos d'água ${ }^{6,7}$. O impacto da descarga de substâncias poluentes nos corpos receptores, como rios e lagos, tem sido muito forte. Uma conseqüência daninha imediata e bastante visível é a morte, cada vez mais freqüente, de peixes e outros organismos aquáticos. Além disso, efeitos subseqüentes como bioacumulação e penetração de compostos tóxicos na cadeia alimentar dos sistemas aquáticos têm sido constantemente detectados em vários corpos d'água ${ }^{8-11}$. Esta situação tem provocando sérios problemas ecológicos e graves consequiências para a saúde e bem estar do homem ${ }^{2,8,12}$.

\section{EFLUENTES INDUSTRIAIS E PROCESSOS DE TRATAMENTO}

Dentre os vários segmentos produtivos que podem degradar a qualidade dos ambientes aquáticos, as indústrias têxteis e papeleiras possuem grande destaque, pois são geradoras de grandes volumes de efluentes, com alta carga orgânica e demanda bioquímica de oxigênio, baixas concentrações de oxigênio dissolvido, forte coloração e pouca biodegradabilidade ${ }^{5,13-17}$. Esses efluentes também possuem grande propensão para alterar ciclos biológicos, devido a sua toxicidade e potencialidades carcinogênicas e mutagênicas ${ }^{18,19}$.

$\mathrm{O}$ potencial poluidor de uma indústria têxtil de pequeno/médio porte equivale ao volume de resíduos gerados por aproximadamente 7.000 pessoas ou, ainda, ao de 20.000 pessoas considerando-se o teor de material orgânico ${ }^{20}$. A etapa de tingimento é uma das mais importantes dentro do processo produtivo têxtil. Infelizmente ela também possui destaque do ponto de vista ambiental, pois cerca de $30 \%$ dos corantes utilizados neste processo não se fixam nas fibras e são descarregados como efluentes nos corpos d'água ${ }^{21-24}$. Para atender à demanda dos clientes por uma enorme variedade de cores e tons, as empresas têxteis têm a sua disposição mais de 10.000 corantes $^{25}$, com destaque para a classe dos azocorantes (grupo cromóforo: $-\mathrm{N}=\mathrm{N}-$ ), que representam cerca de $60 \%$ do mercado mundial de corantes utilizados pelas indústrias têxteis ${ }^{5,26}$. Vários estudos têm demonstrado que os efeitos maléficos da presença de azocorantes nos corpos d'água vão muito além da poluição visual (mudanças na intensidade e na tonalidade da coloração das águas), pois a alteração na penetração da luz devido à interação desta com os corantes pode interferir nos ciclos biológicos da biota aquática, especialmente no processo de fotossíntese e na oxigenação do corpo d'água ${ }^{5,15}$.

Já as indústrias papeleiras são tradicionalmente apontadas como uma das maiores responsáveis pela contaminação do meio ambiente por uma série de compostos organoclorados, os quais originam-se durante os processos de polpação e branqueamento da pasta de celu$\operatorname{lose}^{13}$. Os tipos e as abundâncias dos compostos organoclorados que são gerados variam em função do processo de polpação e de branqueamento adotados, assim como das espécies e origem das árvores utilizadas como matéria-prima ${ }^{13,16}$. De um modo geral, esta classe de compostos poluentes desperta atenção devido a sua propensão à bioconcentração (geralmente são lipossolúveis) e a sua alta toxicidade aguda e crônica (que a torna recalcitrante à degradação biológica) ${ }^{13,19}$.

Os processos de remediação de efluentes mais utilizados pela maioria das indústrias estão baseados em um pré-tratamento por sistemas físico-químicos (ex.: adsorção, coagulação e/ou precipitação) seguido de tratamento biológico, principalmente pelo sistema de lodos ativados ${ }^{5,13}$.
O tratamento físico-químico preliminar permite uma certa depuração dos efluentes. Contudo, os compostos poluentes não são destruídos, pois estes processos somente promovem uma transferência de fase, no caso dos efluentes do meio aquoso para sólido, persistindo o problema do ponto de vista ambiental ${ }^{13}$. Já o tratamento com lodos ativados é um dos sistemas biológicos de degradação de maior eficiência, sendo o mais empregado pela maioria das indús$\operatorname{trias}^{13}$. Devido a sua versatilidade, este método é capaz de remediar uma ampla gama de compostos orgânicos poluentes ${ }^{13}$. O processo consiste basicamente de um tanque de aeração, onde o efluente é adicionado e agitado na presença de microorganismos e ar, nesta etapa ocorre a oxidação da matéria orgânica do efluente. O sistema é dotado ainda de um tanque de sedimentação, no qual são sedimentados os flocos microbiais produzidos durante a fase de oxidação no tanque de aeração $0^{5,13}$. Uma característica do sistema de lodos ativados é a recirculação de grande proporção de biomassa, fazendo com que boa parte dos microorganismos permaneçam por um longo tempo de residência no meio, o que facilita o processo de oxidação dos compostos orgânicos e reduz o tempo de retenção do efluente. Infelizmente, este tipo de processo apresenta os inconvenientes de ser susceptível à composição do efluente (cargas de choque), requere um acompanhamento rigoroso das condições ótimas de $\mathrm{pH}$, temperatura e nutrientes, produz grande volume de lodo e ainda necessita de uma grande área territorial para instalação ${ }^{13}$. Além disso, muitos compostos não são efetivamente degradados pelos microorganismos, principalmente organoclorados e nitroaromáticos, ficando adsorvidos nos flocos de lodo, o que gera um novo problema a respeito da disposição final desta biomassa contaminada (ela acaba atuando apenas como um agente transferidor de fase dos poluentes).

Em função destas limitações, existe uma necessidade imediata de desenvolvimento e utilização de processos que realmente possam degradar, ou preferencialmente mineralizar (conversão dos poluentes orgânicos em $\mathrm{CO}_{2}, \mathrm{H}_{2} \mathrm{O}$ e ácidos minerais, como $\mathrm{HCl}$ ), as espécies poluentes e, assim, garantir a qualidade de nossos recursos hídricos. Com este objetivo, a aplicação dos processos oxidativos avançados (POA) na remediação de compostos poluentes tem sido muito estu$\operatorname{dada}^{27-38}$. Os POA caracterizam-se pela geração de espécies fortemente oxidantes, principalmente radicais hidroxila $\left(\mathrm{OH}^{\circ}\right)$, capazes de promover rapidamente a degradação de vários compostos poluentes ${ }^{27-38}$. De um modo geral, nestes processos a matéria orgânica dissolvida na água é oxidada por uma seqüência de reações em cadeia (muitas das quais envolvem radicais livres) iniciadas, por exemplo, pela abstração de um átomo de hidrogênio do composto poluente alvo pelo radical hidroxila. Os mecanismos, a diversidade e a eficiência dos POA têm sido abordados em uma série de revisões ${ }^{31-36} \mathrm{e}$ não serão detalhados no presente trabalho.

Apesar dos POA serem uma alternativa de tratamento bastante promissora, a geração de $\mathrm{OH}^{*}$ é um processo relativamente caro e apresenta uma série de dificuldades na sua implementação em grande escala, tais como remoção ou imobilização das nanopartículas dos fotocatalisadores, necessidade de fontes de radiação ultravioleta, eletrodos, adição constante de reagentes instáveis como ozônio, peróxidos, etc ${ }^{13,35-38}$. Um outro problema que aumenta o custo da remediação com POA é o consumo dos radicais $\mathrm{OH}^{\bullet}$ em reações paralelas que não levam à degradação dos compostos alvos, por exemplo com íons carbonatos, que transferem um elétron para o $\mathrm{OH}^{*}$ tornando-se ânions radicais carbonato mononegativos, que são inativos na reação com os poluentes ${ }^{2}$.

Alguns compostos com centros deficientes de elétrons, tais como compostos halogenados e/ou nitrogenados, reagem muito lentamente com $\mathrm{OH}^{*}$, não sendo eficientemente degradados pelos POA. A reação de eliminação para essas espécies é muito mais rápida quando as etapas iniciais do processo de degradação são redutivas em vez 
de oxidativas. Nesta abordagem alternativa, o ferro de valência zero surge como uma ferramenta promissora para a remediação destas importantes classes de compostos poluentes.

\section{REMEDIAÇÃO COM FERRO DE VALÊNCIA ZERO}

Há muito tempo sabe-se que a presença de compostos orgânicos em meio aquoso pode acelerar a corrosão de materiais metálicos, principalmente os à base de ferro ${ }^{39}$. Desta maneira, chega a ser surpreendente que a reação inversa, ou seja, a modificação/degradação de compostos orgânicos por metais de valência zero, não tenha recebido muita atenção até o final do século passado ${ }^{39}$. A primeira aplicação ambiental deste tipo de processo foi documentada, na forma de patente, somente em $1972^{40}$. Contudo, o volume de trabalhos sobre a remediação de compostos poluentes via degradação redutiva com metais elementares só tornou-se expressivo na década de $90^{41-43}$. Vários metais (tais como $\mathrm{Zn}, \mathrm{Sn}, \mathrm{Pt}$, etc) podem ser utilizados neste tipo de degradação, mas o emprego de ferro tem merecido grande destaque ${ }^{41-43}$.

O ferro é o quarto elemento mais abundante da crosta terrestre, representando $6,2 \%$ de seu peso ${ }^{44}$. $\mathrm{O}$ ferro faz parte da cultura humana há séculos, sendo que suas propriedades físicas e químicas lhe conferem uma enorme importância nos mais diversos ramos produtivos. Recentemente, sua gama de aplicações ampliou-se, já que o ferro de valência zero tem atraído grande interesse como ferramenta de remediação ambiental devido a sua eficiência na degradação de compostos recalcitrantes, facilidade de obtenção, baixo custo e compatibilidade ambiental (não é um elemento tóxico) ${ }^{45}$.

O par redox formado pelo ferro metálico (estado de oxidação zero, $\mathrm{Fe}^{0}$ ) e o íon ferroso (estado de oxidação +2, $\mathrm{Fe}^{2+}$ ) (Equação 1) possui um potencial padrão de redução igual a $-0,440 \mathrm{~V}^{46}$.

$\mathrm{Fe}^{2+}+2 \mathrm{e}^{-} \rightleftarrows \mathrm{Fe}^{0}$

Este valor mostra que o $\mathrm{Fe}^{0}$ é um agente redutor relativamente forte frente a uma série de substâncias, tais como íons hidrogênio, carbonatos, sulfatos, nitratos e oxigênio e muitos compostos orgâni$\cos$ (principalmente organoclorados e nitroaromáticos). Assim, a corrosão do ferro zero é um processo eletroquímico no qual a oxidação do $\mathrm{Fe}^{0}$ a $\mathrm{Fe}^{2+}$ é a semi-reação anódica. Sendo que a reação catódica associada varia de acordo com a reatividade das espécies aceptoras de elétrons presentes no meio.

Em meio aquoso puramente anóxido, os aceptores são $\mathrm{H}^{+}$e $\mathrm{H}_{2} \mathrm{O}$, cujas reduções produzem $\mathrm{OH}^{-}$e $\mathrm{H}_{2}$. $\mathrm{O}$ processo global de corrosão do $\mathrm{Fe}^{0}$ em um sistema anaeróbio é descrito pelas Equações 2 e/ou 3:

$\mathrm{Fe}^{0}+2 \mathrm{H}^{+} \rightleftarrows \mathrm{Fe}^{2+}+\mathrm{H}_{2}$

$\mathrm{Fe}^{0}+2 \mathrm{H}_{2} \mathrm{O} \rightleftarrows \mathrm{Fe}^{2+}+\mathrm{H}_{2}+\mathrm{OH}^{-}$

A semi-reação catódica sob condições aeróbias envolve o $\mathrm{O}_{2}$ como aceptor de elétrons. Neste caso, a reação com ferro produzirá somente $\mathrm{OH}^{-}$(e não $\mathrm{H}_{2}$ ) (Equação 4):

$2 \mathrm{Fe}^{0}+\mathrm{O}_{2}+2 \mathrm{H}_{2} \mathrm{O} \rightleftarrows 2 \mathrm{Fe}^{2+}+4 \mathrm{OH}^{-}$

Tanto em regime aeróbio quanto anaeróbio há um aumento no valor do $\mathrm{pH}$ se os sistemas não forem tamponados. Entretanto, este efeito é mais pronunciado sobre condições aeróbias, conforme mostra a estequiometria das Equações 3 e 4 . $\mathrm{O}$ aumento do $\mathrm{pH}$ favorece a formação de precipitados de hidróxido de ferro ${ }^{47}$, os quais podem eventualmente formar uma camada sobre a superfície do metal e inibir sua reatividade.

Tal como mencionado anteriormente, compostos orgânicos (por exemplo, os halogenados - RX) também podem ser reduzidos por ferro zero. Na presença de doadores de elétrons os haletos de alquila, por exemplo, tipicamente sofrem um processo de dealogenação redutiva (Equação 5):

$\mathrm{RX}+2 \mathrm{e}^{-}+\mathrm{H}^{+} \rightleftarrows \mathrm{RH}+\mathrm{X}^{-}$

A semi-reação catódica de uma série de haletos de alquila apresenta potenciais padrão de redução que variam entre $+0,5$ e $+1,5 \mathrm{~V}$ $\left(\mathrm{em} \mathrm{pH} \mathrm{7)}{ }^{48}\right.$. Assim, a reação global entre as Equações 1 e 5 (Equação 6) costuma ser realizada sob condições termodinâmicas muito favoráveis.

$\mathrm{Fe}^{0}+\mathrm{RX}+\mathrm{H}^{+} \rightleftarrows \mathrm{Fe}^{2+}+\mathrm{RH}+\mathrm{X}^{-}$

A Equação 6 pertence a uma classe de reações muito bem conhecidas e que tem sido usada em síntese orgânica por mais de 150 $\operatorname{anos}^{45,50}$.

Em um sistema aquoso com ferro de valência zero, além do $\mathrm{Fe}^{0}$ e do $\mathrm{H}_{2}, \mathrm{o} \mathrm{Fe}^{2+}$ também pode atuar como espécie redutiva, tal como demonstrado na Equação 7. Os íons ferrosos são agentes redutores capazes de promover a dealogenação de alguns haletos de alquila, mas estas reações costumam apresentar uma cinética muito lenta ${ }^{45,51}$.

$2 \mathrm{Fe}^{2+}+\mathrm{RX}+\mathrm{H}^{+} \rightleftarrows 2 \mathrm{Fe}^{3+}+\mathrm{RH}+\mathrm{X}^{-}$

Assim, há três rotas básicas pelas quais o processo de degradação redutiva com ferro de valência zero pode promover a dealogenação de organoclorados em meio aquoso ${ }^{45}$ (Figura 1). A primeira rota é através da transferência direta de elétrons do $\mathrm{Fe}^{0}$ para o haleto de alquila adsorvido na superfície metálica. $\mathrm{O}$ segundo caminho envolve a reação dos compostos orgânicos com $\mathrm{Fe}^{2+}$, que é gerado no processo de corrosão do $\mathrm{Fe}^{0}$. Finalmente, a terceira via tem $\mathrm{o}_{2}$, produzido como um produto da corrosão do $\mathrm{Fe}^{0}$ pela água, como agente redutor (Equação 8). Neste último caso, a reação do $\mathrm{H}_{2}$ com os compostos poluentes não é efetiva na ausência de catalisadores. De fato, o acúmulo excessivo de $\mathrm{H}_{2}$ sobre a superfície do metal costuma inibir o processo de corrosão e dificultar as reações de redução dos compostos alvos. Felizmente, a própria superfície do ferro metá-
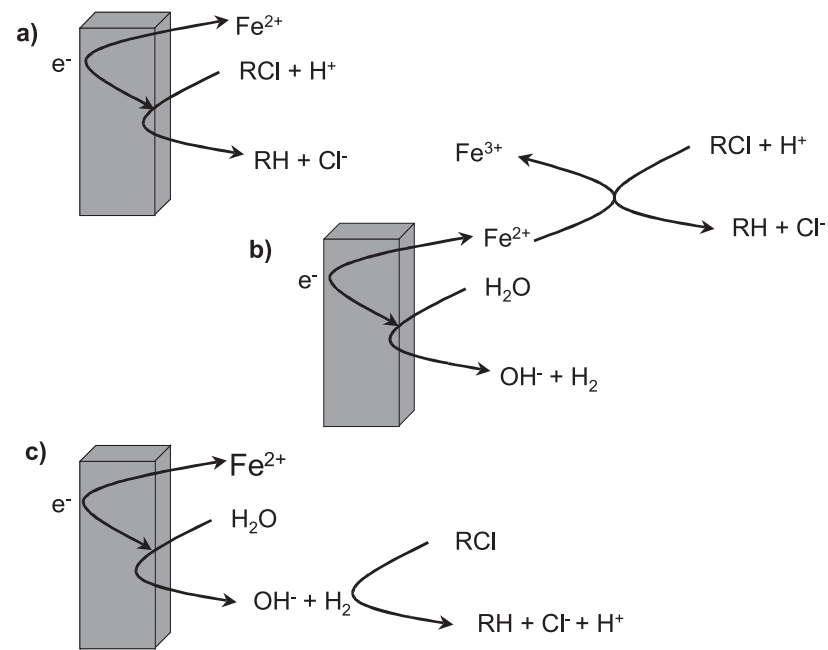

Figura 1. Rotas de dealogenação de organoclorados em sistema $\mathrm{Fe}^{0}-\mathrm{H}_{2} \mathrm{O}$ : a) transferência direta de elétrons da superfície metálica para o organoclorado adsorvido na superfície do $\mathrm{Fe}^{o}$; b) redução do composto alvo pelo $\mathrm{Fe}^{2+}$ produzido pela corrosão do ferro metálico; c) hidrogenação do poluente organoclorado pelo $\mathrm{H}_{2}$ formado em condições anaeróbias 
lico ou outras partículas sólidas presentes no meio podem atuar como catalisadores deste processo ${ }^{45}$.

$\mathrm{H}_{2}+\mathrm{RX} \rightleftarrows \mathrm{RH}+\mathrm{H}^{+}+\mathrm{X}^{-}$

A definição de qual rota é seguida preferencialmente durante a degradação dos compostos alvos pelo processo com ferro zero depende de uma série de fatores experimentais e ainda é objeto de muitos estudos ${ }^{39-43,45-49,51-75}$

\section{APLICAÇÕES DO PROCESSO REDUTIVO COM Fe ${ }^{0}$}

Um dos trabalhos mais representativos a respeito da potencialidade e aplicabilidade do processo de remediação via degradação redutiva com $\mathrm{Fe}^{0}$ foi realizado por Gillham e colaboradores ${ }^{49}$. Os autores desenvolveram uma técnica in situ promissora para o tratamento de águas subterrâneas contaminadas por compostos orgânicos clorados voláteis. O processo foi baseado na construção de uma "parede" permeável perpendicular à direção do fluxo de água subterrânea, conforme mostra a Figura 2. Esta parede era constituída de camadas de areia, entre as quais foi adicionado ferro metálico na forma de pequenos grânulos. Durante o processo de difusão dos compostos poluentes através da parede, havia a interação destes com o $\mathrm{Fe}^{0}$ que promovia sua dealogenação, obtendo-se água purificada sem necessidade do seu bombeamento para fora do subsolo. Um aspecto importante a ser destacado é que a fonte de ferro zero empregada era um produto de descarte de uma série de processos de manufatura (exemplo: metalúrgicos). Assim, os processos de degradação com $\mathrm{Fe}^{0}$ apresentam a vantagem adicional de permitirem a reutilização de rejeitos como agentes ativos na depuração e conservação da qualidade do meio ambiente.

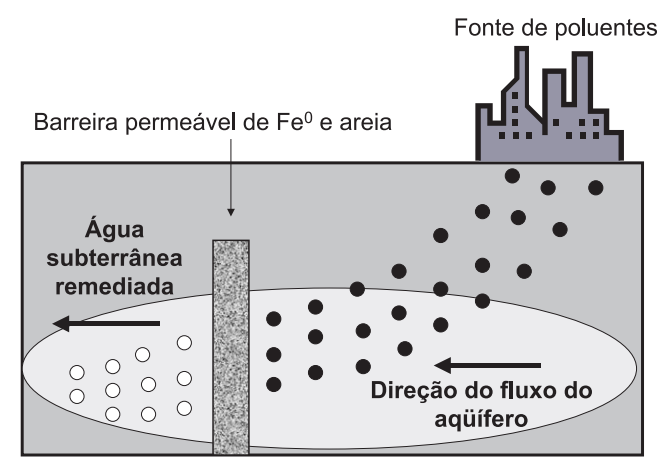

Figura 2. Parede permeável, constituída por grânulos de areia e ferro metálico, utilizada na descontaminação de águas subterrâneas contaminadas com compostos organoclorados

Os experimentos reais em campo, realizados por Gillham e colaboradores ${ }^{49}$, mostraram que essa nova tecnologia pode funcionar com sucesso durante vários anos, podendo substituir, no futuro, os métodos de "bombeamento e tratamento" que atualmente são os mais utilizados para a remediação de águas subterrâneas contaminadas com compostos poluentes ${ }^{2}$, uma vez que os métodos biológicos e os POA não possuem a versatilidade necessária para serem aplicados diretamente neste tipo de situação. Estes processos apresentam esta limitação devido, dentre outros fatores, à necessidade de adição contínua de reagentes; controle de $\mathrm{pH}$, temperatura, concentração de oxigênio; emprego de reatores específicos para manter as condições ideais à manutenção microbiana (no caso de processo biológico) ou geração das espécies radicalares (no caso de POA, onde geralmente emprega-se reatores fotoquímicos, eletroquímicos ou ozonizadores);

etc. A versatilidade na implementação de processos remediativos em situações reais, sem a dependência de infra-estruturas elaboradas e/ ou complexas, é outra grande vantagem apresentada pelo processo de remediação com ferro de valência zero.

Gillham e O'Hannesin ${ }^{39}$ realizaram uma estimativa que realça a principal vantagem do processo com $\mathrm{Fe}^{0}$, que é sua ótima razão custo/benefício. Baseando-se somente na transferência de elétrons entre a superfície do ferro metálico e espécies organocloradas, os autores calcularam que cerca de $1 \mathrm{~kg}$ de $\mathrm{Fe}^{0}$ é suficiente para promover a completa descloração de aproximadamente $500 \mathrm{~m}^{3}$ de água contendo tetraclorometano na concentração de $1 \mathrm{mg} \mathrm{L}^{-1}$.

Há uma série de outros exemplos da eficiência do processo com $\mathrm{Fe}^{0}$ na degradação de ampla gama de compostos organoclora$\operatorname{dos}^{45,53-65}$. Dentre eles destaca-se o trabalho realizado por Ghauch ${ }^{64}$, que estudou a redução de alguns pesticidas organoclorados (Benomyl, Dicamba e Picloram, Figura 3) pela ação do $\mathrm{Fe}^{0} \mathrm{em}$ um reator cônico. Ghauch observou a completa degradação do pesticida Dicamba em 40 min de interação com $\mathrm{Fe}^{0}$; já o Benomyl foi totalmente degradado em apenas 25 min de tratamento; mas o melhor resultado foi obtido com a remediação do pesticida Picloram que foi completamente eliminado em cerca de 10 min de tratamento. Esta ordem de eficiência corrobora o fato de que quanto mais deficiente de elétrons for o composto a ser degradado (no caso o Picloram), mais susceptível/favorável será sua redução por $\mathrm{Fe}^{039,64}$.

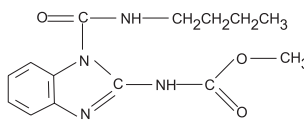

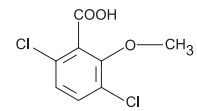

(b)

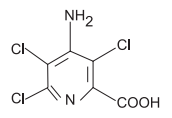

(c)

Figura 3. Estrutura dos pesticidas organoclorados benomyl (a); dicamba (b) e picloram (c)

Sayles e colaboradores ${ }^{65}$ também estudaram o emprego do processo com $\mathrm{Fe}^{0}$ na degradação de pesticidas organoclorados, especificamente do DDT (1,1,1-tricloro-2,2-bis(p-clorofenil)etano) e de suas impurezas como o DDD (1,1-dicloro-2,2-bis(p-clorofenil)etano) e DDE (2,2-bis(p-clorofenil)-1,1-dicloroetileno). Os autores escolheram estes compostos já que o DDT foi um dos pesticidas mais utilizados no mundo inteiro até a década de 70, e ainda continua sendo muito empregado em alguns países. Este composto está na lista dos poluentes prioritários da EPA (agência de proteção ambiental dos Estados Unidos) e possui poucas alternativas seguras para sua destruição, sendo a incineração um dos métodos mais empregados para este fimm ${ }^{65}$. A degradação com $\mathrm{Fe}^{0}$ é uma alternativa atraente devido às suas várias vantagens já exploradas neste texto e também por não apresentar risco de formação de sub-produtos de degradação com toxicidades muitas vezes superiores aos produtos originais (tais como dioxinas e furanos, que são tradicionalmente apontados como sub-produtos da incineração de compostos poluentes clorados). Sayles e colaboradores ${ }^{65}$ conduziram os experimentos sobre remediação do DDT em reatores anaeróbios (em batelada) sob condições de pH neutro e agitação contínua. Os resultados obtidos mostraram que, em 20 dias de tratamento, a taxa de degradação dos poluentes prioritários DDD e DDE foi de 93\% e para o DDT, cerca de $99 \%$.

Além dos organoclorados, há vários estudos sobre o emprego de $\mathrm{Fe}^{0}$ na degradação de outras classes de compostos poluentes (que também apresentam centros deficientes de elétrons) $)^{66-75,77-79,83,84}$. Westerhoff e James ${ }^{75}$ avaliaram a degradação redutiva de nitratos por 
meio de ferro em pó. Os autores utilizaram uma coluna recheada com $\mathrm{Fe}^{0}$, pela qual passavam continuamente soluções contendo concentrações conhecidas de nitrato. Parâmetros como pH, oxigênio dissolvido, tempo de residência e tamanho de partícula do pó foram monitorados. Concluíram que a degradação do nitrato é acompanhada pela redução da quantidade de oxigênio dissolvido, pela solubilização de íons de ferro e pelo aumento do $\mathrm{pH}$. O aumento do $\mathrm{pH}$ em função da remoção de nitrato pode ser explicado pela Equação 9, que mostra o consumo estequiométrico de $10 \mathrm{~mol}$ de prótons durante a conversão dos íons nitrato em íons amônio:

$\mathrm{NO}_{3}^{-}+10 \mathrm{H}^{+}+4 \mathrm{Fe}^{0} \longrightarrow \mathrm{NH}_{4}^{+}+3 \mathrm{H}_{2} \mathrm{O}+4 \mathrm{Fe}^{2+}$

O aumento do valor do $\mathrm{pH}$ devido ao consumo de prótons diminui a solubilidade do ferro e conduz à precipitação do mesmo. Assim, em valores baixos de $\mathrm{pH}$ a degradação é maior, pois inibe a deposição de ferro em solução.

Larson e Weber ${ }^{76}$ verificaram que na presença de $\mathrm{Fe}^{0}$ compostos azoaromáticos são reduzidos para aminas aromáticas pela quebra da ligação $-\mathrm{N}=\mathrm{N}$ - dos grupos azos, permitindo a descoloração de soluções contendo estes corantes/pigmentos. Com base nesta informação, Cao e colaboradores ${ }^{77}$ aplicaram $\mathrm{Fe}^{0}$ (na forma de pó) na degradação de soluções aquosas de azocorantes, simulando um efluente de indústria têxtil. Os azocorantes utilizados foram o alaranjado I, alaranjado ácido II, alaranjado ácido IV, alaranjado ácido GG e vermelho ácido 3B. Os resultados obtidos mostraram que o pré-tratamento superficial das partículas de ferro com $\mathrm{HCl}$ conduziu a um aumento na eficiência da degradação dos compostos poluentes alvos, pois as camadas de óxidos sobre a superfície do ferro metálico são removidas, propiciando maior área superficial efetiva. Paralelamente, o aumento da acidez também contribuiu para melhorar a eficiência do processo remediativo pois, conforme mencionado, durante a degradação das moléculas dos azocorantes há um consumo de prótons. Se não houver a adição de $\mathrm{H}^{+}$(acidificação) pode haver um aumento do valor de $\mathrm{pH}$ e, conseqüentemente, diminuição da solubilidade dos íons de ferro que podem depositar-se na superfície do metal na forma de hidróxidos, impedindo/dificultando o processo de transferência de elétrons entre o $\mathrm{Fe}^{0}$ e os compostos a serem degradados.

Nam e Tratnyek ${ }^{78}$ estudaram a redução de uma ampla gama de azocorantes, empregando $\mathrm{Fe}^{0}$ sob condições anaeróbias e pH neutro. Os experimentos consistiram em aplicar ferro de valência zero na forma granular em reatores contendo separadamente os respectivos azocorantes. Dentre vários resultados promissores, os autores constataram que a degradação do corante alaranjado II é dada preferencialmente pela clivagem do grupo azo, levando à formação de ácido sulfanílico e 1-amino-2-naftol. Todas as soluções de azocorantes tratadas com $\mathrm{Fe}^{0}$ foram rapidamente descolorizadas pela redução do grupo azo, obtendo-se sub-produtos não cromóforos.

Roy e colaboradores ${ }^{79}$ também empregaram a degradação redutiva com $\mathrm{Fe}^{0}$ (usando cubos de ferro metálico) para o tratamento do corante alaranjado ácido II, sob condições aeróbias e anaeróbias. No processo sob atmosfera inerte todo alaranjado ácido II foi degradado e somente dois compostos estáveis foram detectados: 1,2-diidroxinaftaleno e benzeno, nenhum outro fragmento do azocorante ou grupos contendo função sulfonada foram identificados; segundo os autores, caso tenha ocorrido a formação de outros compostos, estes apresentaram alta volatilidade e não puderam ser observados nas condições experimentais utilizadas. O mecanismo de degradação anaeróbio proposto é apresentado na Figura 4, onde pode-se observar uma etapa de adsorção do grupo sulfonado à superfície do metal e as subseqüentes etapas redutivas. No tratamento oxidativo, os pesquisadores observaram que sob condições aeróbias ocorrem dois fenômenos

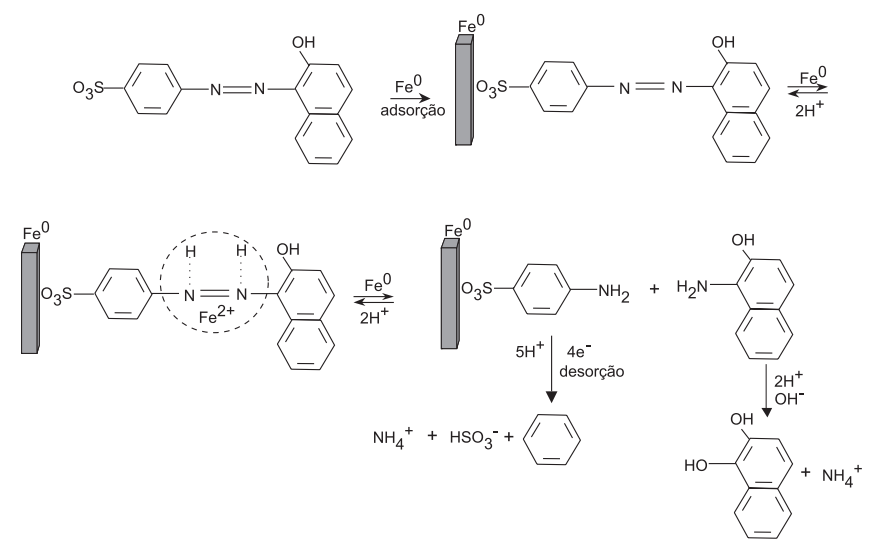

Figura 4. Mecanismo anaeróbio da degradação do azocorante alaranjado ácido II empregando-se $\mathrm{Fe}^{0}$

químicos: o primeiro consiste na redução da molécula do alaranjado ácido II pelo processo de degradação redutiva com $\mathrm{Fe}^{0} \mathrm{e}$ o segundo conduz à oxidação dos produtos, formados durante a etapa de redução, por reações do tipo Fenton. Segundo Roy e colaboradores ${ }^{79}$ a presença de $\mathrm{O}_{2} \mathrm{e} \mathrm{Fe}^{0} \mathrm{em}$ meio ácido proporciona condições reacionais favoráveis à formação de peróxido de hidrogênio ${ }^{80}$. O mecanismo deste processo envolve vários estágios, iniciando com a redução do oxigênio dissolvido e a formação de radicais superóxido $\mathrm{O}_{2}$ que reagem rapidamente com $\mathrm{H}^{+}$para formar radicais peróxido $\mathrm{HO}_{2}$, que por sua vez são instáveis e conduzem à formação de peróxido de hidrogênio. A interação entre $\mathrm{H}_{2} \mathrm{O}_{2}$ e os íons de $\mathrm{Fe}^{2+}$ (oriundos da oxidação do $\mathrm{Fe}^{0}$ ) pode levar à formação de radicais hidroxila (caracterizando a clássica reação de Fenton, Equação 10), que são espécies com grande potencial de oxidação, capazes de degradar eficientemente muitos compostos orgânicos recalcitrantes. A seqüiência de etapas do processo de degradação com $\mathrm{Fe}^{0}$ sob condições aeróbias e anaeróbias está esquematizada na Figura 5.

$\mathrm{Fe}^{2+}+\mathrm{H}_{2} \mathrm{O}_{2} \longrightarrow \mathrm{Fe}^{3+}+\mathrm{OH}+\mathrm{OH}^{-}$

De modo geral, o tratamento com ferro de valência zero restringe-se à redução dos grupos funcionais dos compostos orgânicos poluentes, assim, apesar deste processo permitir uma degradação/ transformação efetiva dos compostos poluentes, ele é limitado quanto à mineralização destas espécies. $\mathrm{O}$ trabalho descrito acima mostra que esta limitação pode ser eficazmente contornada empregando-se $\mathrm{Fe}^{0}$ sob condições que permitam a geração de espécies fortemente

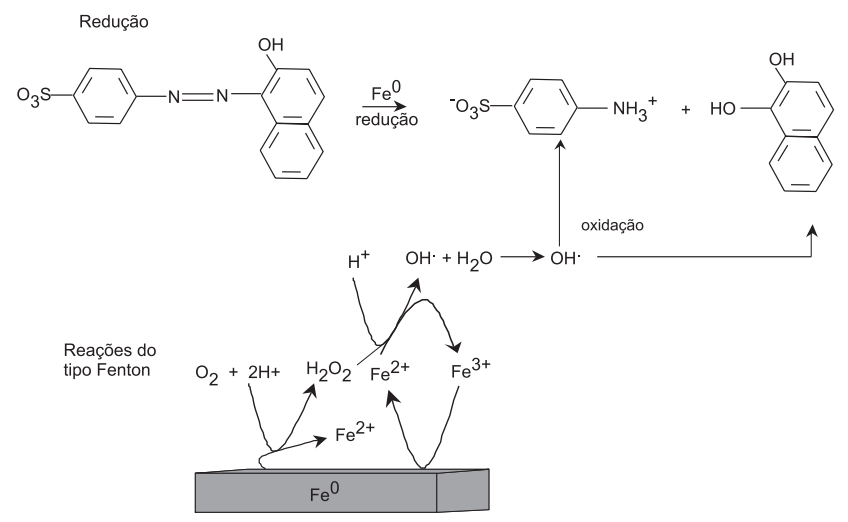

Figura 5. Mecanismo aeróbio da degradação do azocorante alaranjado ácido II empregando-se $\mathrm{Fe}^{0}$ 
oxidantes. Alguns trabalhos têm empregado o $\mathrm{Fe}^{0}$ como fonte de $\mathrm{Fe}^{2+}$ para processos de Fenton/foto-Fenton ${ }^{81,82}$, entretanto a abordagem mais promissora parece ser a combinação entre o processo degradativo com $\mathrm{Fe}^{0}$ e os POA. Nesta abordagem pode-se obter uma excelente sinergia, onde um tipo de processo pode suprir deficiências do outro, permitindo atingir níveis muito significativos de degradação e mineralização de uma série de espécies poluentes recalcitrantes.

Buscando-se este aumento na eficiência dos processos remediativos, Deng e colaboradores ${ }^{83}$ estudaram a descoloração de uma série de corantes em solução aquosa, utilizando a associação entre os tratamentos com $\mathrm{Fe}^{0}$ e com radiação UV. Os experimentos foram conduzidos em três diferentes condições: emprego de UV e $\mathrm{Fe}^{0}$ de forma isolada e combinação dos dois métodos $\left(\mathrm{UV} / \mathrm{Fe}^{0}\right)$. Os resultados obtidos mostraram que a descoloração fotoquímica (UV) não foi significativa, com degradações inferiores a $5 \%$. O processo com $\mathrm{Fe}^{0}$ foi muito mais eficiente, permitindo níveis de degradação dos corantes, no mesmo tempo de tratamento, superiores a 50\%. Entretanto, a combinação entre $\mathrm{Fe}^{0}$ e o processo com UV apresentou um efeito sinérgico significativo, aumentando a eficiência na descoloração dos diferentes corantes em até $10 \%$.

Oh e colaboradores ${ }^{84}$ estudaram a degradação de 2,4 trinitrotolueno (TNT) e hexaidro-1,3,5-trinitro-1,3,5-triazina (RDX), compostos que são comumente encontrados em água rosada (efluente do processo produtivo de explosivos de uso militar). O tratamento biológico convencional por lodos ativados é pouco efetivo para remediar este tipo de efluente. Os processos oxidativos avançados também apresentam grandes limitações na degradação destes compostos ${ }^{85}$. Desta forma, os autores utilizaram a associação dos tratamentos oxidativos por reagente de Fenton e $\mathrm{Fe}^{0}$. Na metodologia proposta o $\mathrm{Fe}^{0}$ foi utilizado como agente redutor destes compostos recalcitrantes, visando a obtenção de produtos mais susceptíveis aos subseqüentes tratamentos por processos oxidativos. Soluções de TNT e RDX foram, assim, primeiro reduzidas em um reator com $\mathrm{Fe}^{0}$ granulado, sendo os produtos deste processo subseqüentemente oxidados por reagente de Fenton $\left(\mathrm{H}_{2} \mathrm{O}_{2} / \mathrm{Fe}^{2+}\right)$. Após $1 \mathrm{~h}$ de tratamento foi possível degradar $93,5 \%$ do TNT e totalmente o RDX. O rendimento na degradação do RDX foi maior que o TNT devido à maior eficiência do pré-tratamento com $\mathrm{Fe}^{0}$ na clivagem do anel de triazina do $\mathrm{RDX}^{86}$.

\section{CONCLUSÕES}

A sociedade contemporânea atingiu um nível de desenvolvimento nunca antes observado. Apesar deste desenvolvimento propiciar uma série de efeitos benéficos sobre a expectativa e qualidade de vida das pessoas (novos medicamentos, bens, produtos, serviços, etc), ele também contribui para o aumento constante da população mundial e, paralelamente, das atividades produtivas que visam suprir as necessidades desta massa populacional, que têm trazido várias conseqüências para o meio ambiente, quer pelo aumento na utilização dos recursos naturais (especificamente do consumo de água) ou pelo incremento na qualidade e na complexidade dos resíduos tóxicos lançados no ambiente. As alterações ambientais devido à ação antrópica têm atingido níveis extremamente preocupantes, resultando numa redução significativa na qualidade do solo, do ar e da água.

Estas alterações têm trazido à nossa civilização um novo desafio: a correta utilização desse precioso líquido. Diante desta delicada situação, há uma necessidade urgente de técnicas alternativas para a remediação de ampla gama de resíduos, que sejam rápidas, eficientes e de baixo custo. Dentro deste contexto, o emprego do ferro de valência zero tem demonstrado grandes perspectivas na degradação de compostos poluentes, principalmente os organoclorados e nitrogenados, duas classes de compostos orgânicos que, normalmente, não são eficazmente remediadas pelos processos tradicionais de tratamento de efluentes (quer biológicos, quer oxidativos avançados). É importante salientar que nenhum processo de tratamento, desenvolvido até o presente momento, é capaz de se apresentar como uma alternativa única que possa ser empregada eficientemente na remediação de vasta gama de compostos poluentes.

Apesar disto, a ampliação de aplicabilidade dos processos redutivos com ferro zero tem sido objeto de esforços constantes e de novos estudos. Com este objetivo, pesquisas estão sendo direcionadas para que esta técnica possa ser utilizada na remediação de solos e corpos d'água contaminados com metais pesados altamente oxidados, como por exemplo, a redução do tóxico $\mathrm{Cr}^{6+}$ (espécie normalmente solúvel nas condições apresentadas pelas águas naturais e, portanto, com alto potencial para contaminar grandes áreas) para o menos impactante $\mathrm{Cr}^{3+}$ (geralmente sobre a forma de óxidos insolúveis).

Um outro campo de desenvolvimento do processo com ferro zero é quanto a sua eficiência. Pesquisas recentes têm apontado que a modificação da superfície de ferro metálico pode contribuir em muito para melhorar o processo de transferência de elétrons e para aumentar o sobrepotencial de reações interferentes paralelas (por exemplo, a reação com água, que acaba competindo pelos elétrons, e o consequiente desprendimento de hidrogênio diminui a eficiência da reação de degradação dos poluentes alvos), há indícios que o revestimento de limalhas de ferro com níquel aumenta a velocidade de degradação dos compostos orgânicos por um fator de dez. Essas modificações têm sugerido que o processo de remediação com ferro zero pode tornar-se mais promissor que se supõe atualmente e evidenciam um amplo campo de pesquisa a ser explorado.

\section{AGRADECIMENTOS}

Ao CNPq e FAPESP pelo apoio financeiro.

\section{REFERÊNCIAS}

1. http://www.aguaonline.com.br, acessada em Janeiro 2004.

2. Baird, C.; Química Ambiental, $2^{\mathrm{a}}$ ed., Bookman: Porto Alegre, 2002.

3. Rebouças, A.; Águas Doces no Brasil - Capital Ecológico, Uso e Conservação, $2^{\mathrm{a}}$ ed., Escrituras: São Paulo, 2002.

4. Anastas, P. T.; Kirchhoff, M. M.; Acc. Chem. Res. 2002, 35, 686.

5. Kunz, A.; Peralta-Zamora, P.; Moraes, S. G.; Duran, N.; Quim. Nova 2002, 25,78 .

6. Jungclaus, G. A.; Lopez-Ávila, V.; Hites, R. A.; Environ. Sci. Technol. 1978, 12,88 .

7. Stahl, R. G. J.; The Genetic Toxicology of Organic Compounds in Natural Water and Wastewater, Ecotoxicology and Environmental Safety: New York, 1991.

8. Houk, V. S.; Mutat. Res. 1992, 277, 91.

9. Saxena, J.; Rev. Microbiol. 1984, 15, 1.

10. Metcalfe, C. D.; Cairns, V. W.; Fitzsimans, J. D.; J. Fish. Aquat. Sci. 1988, $45,2161$.

11. Environment Canadá, 1995, EPC - $98 E$.

12. Bitton, G.; Dutka, B. J.; Toxicity Testing Using Microorganisms, CRC Press Inc.: Flórida, 1986

13. Freire, R. S.; Pelegrini, R.; Kubota, L. T.; Duran, N.; Peralta-Zamora, P.; Quim. Nova 2000, 23, 504.

14. Slokar, Y. M.; Marechal, A. M. L.; Dyes Pigm. 1998, 37, 335.

15. Cisneros, R. L.; Espinoza, A. G.; Litter, M. I.; Chemosphere 2002, 48, 393.

16. Thompson, G.; Swain, J.; Kay, M.; Forster, C. F.; Bioresour. Technol. 2001, 77, 275.

17. Freire, R. S.; Thongngamdee, S.; Durán, N; Wang, J.; Kubota, L. T.; Analyst 2001, 127, 258.

18. Chung, K. T.; Cerniglia, C. E.; Mutat. Res. 1992, 277, 201.

19. Brown, M. A.; Devito, S. C.; Crit. Rev. Environ. Sci. Technol. 1993, 23, 249.

20. Moraes, S. G.; Freire, R. S.; Durán, N.; Chemosphere 2000, 40, 369.

21. Zollinger, H.; Color Chemistry, $2^{\text {a }}$ ed., V.C.H. Publishers: New York, 1991.

22. Clarke, E. A.; Anliker, R. Em Handbook of Environmental Chemistry; Hutzinger, O., ed.; 1980, vol. 3A. 
23. Weber, E. J.; Stichney, V. C.; Water Res. 1993, 27, 63.

24. O’Neill, C.; Hawkes, F. R.; Hawkes, D. L.; Lourenco, N. D.; Pinheiro, H. M.; Delee, W.; J. Chem. Technol. Biotechnol. 1999, 74, 1009.

25. Guaratini, C. C. I.; Zanoni, M. V. B.; Quim. Nova 2000, 23, 71

26. Vandevivere, P. V.; Bianch, R.; Verstraete, W.; J. Chem. Technol. Biotechnol. 1998, 72, 289.

27. Park, T. J.; Lee, K. H.; Jung, E. J.; Kim, C. W.; Water Sci. Technol. 1999, 39, 189.

28. Solozhenko, E. G.; Soboleva, N. M.; Goncharuk, V. V.; Water Res. 1995, 29, 2206.

29. Neamtu, M.; Yediler, A.; Siminiceanu, I.; Macoveanu, M.; Kettrup, A.; Dyes Pigm. 2003, 60, 61.

30. Malik, P. K.; Saha, S. K.; Sep. Purif. Technol. 2003, 31, 241.

31. Pirkanniemi, K.; Sillanpaa, M.; Chemosphere 2002, 48, 1047.

32. Chiron, S.; Fernandez-Alba, A.; Rodriguez, A.; Garcia-Calvo, E.; Water Res. 1999, 34, 366.

33. Bhatkhande, D. S.; Pangarkar, V. G.; Beenackers, A. A. C. M.; J. Chem. Technol. Biotechnol. 2001, 77, 102.

34. Litter, M. I.; Appl. Catal., B 1999, 23, 89.

35. Neyens, E.; Baeyens, J.; J. Hazard. Mater. 2002, B98, 33

36. Pêra-Titus, M.; García-Molina, V.; Baños, M. A.; Jiménez, J.; Espulgas, S.; Appl. Catal., B 2004, 47, 219.

37. Kwon, B. G.; Lee, S. D.; Kang, N.; Yoon, J.; Water Res. 1999, 33, 2110

38. Esplugas, S.; Giménez, J.; Contreras, S.; Pascual, E.; Rodríguez, M.; Water Res. 2002, 36, 1034.

39. Gillham, R. W.; O'Hannesin, S. F.; Ground Water 1994, 32, 958.

40. Sweeny, K. H.; Fischer, J. R.; US pat. 3,640,821 1972.

41. Zhang, W. X.; J. Nanop. Res. 2003, 5, 323.

42. Wang, C. B.; Zhang, W. X.; Environ. Sci. Technol. 1997, 31, 2154.

43. Morales, J.; Hutcheson, R.; Cheng, I. F.; J. Hazard. Mater. 2002, B90, 97.

44. Lee, J. D.; Química Inorgânica não tão Consisa, $5^{\mathrm{a}}$ ed., Edgard Blücher: São Paulo, 1999.

45. Matheson, L. J.; Tratnyek, P. G.; Environ. Sci. Technol. 1994, 28, 2045.

46. Bratsch, S. G.; J. Phys. Chem. 1989, 18, 1.

47. Agrawal, A.; Tratnyek, P. G.; Environ. Sci. Technol. 1996, 30,153.

48. Vogel, T. M.; Criddle, C. S.; McCarty, P. L.; Environ. Sci. Technol. 1987, 21,722

49. Guilham, R. W.; Advances in Groundwater Poluttion Control and Remediation, Kluwer Academic Publishers: Dordrecht, 1996.

50. Hudlicky, M.; Reductions in Organic Chemistry, Ellis Horwood: Chichester, 1984.

51. Doong, R. A.; Wu, S. C.; Chemosphere 1992, 24, 1063.

52. Scherer, M. M.; Westall, J. C.; Ziomek-Moroz, M.; Tratnyek, P. G.; Environ. Sci. Technol. 1997, 31, 2385.

53. Orth, W. S.; Gillham, R. W.; Environ. Sci. Technol. 1996, 30, 66.

54. Ghauch, A.; Suptil, J.; Chemosphere 2000, 41, 1835.
55. Chen, L. J.; Al-Abed, S. R.; Ryan, J. A.; Li, Z.; J. Hazard. Mater. 2001, B83, 243.

56. Farrell, J.; Kason, M.; Melitas, N.; Li, T.; Environ. Sci. Technol. 2000, 34, 514

57. Johnson, T. L.; Scherer, M. M.; Tratnyek, P. G.; Environ. Sci. Technol. 1996, 30, 2634.

58. Scherer, M. M.; Balko, B. A.; Gallagher, D. A.; Tratnyek, P. G.; Environ. Sci. Technol. 1998, 32, 3026.

59. Lin, S. H.; Chang, C. C.; Water Res. 2000, 34, 4243.

60. Pérez, M.; Torrades, F.; Domènech, X.; Peral, J.; Water Res. 2002, 36, 2703.

61. McGuire, M. M.; Carlson, D. L.; Vikesland, P. J.; Kohn, T.; Grenier, A. C.; Langley, L. A.; Roberts, A. L.; Fairbrother, D. H.; Anal. Chim. Acta 2003, 496, 301.

62. Kim, H. Y.; Carraway, E. R.; Environ. Sci. Technol. 2000, 34, 2014.

63. Venkatapathy, R.; Bessingpas, D. G.; Canônica, S.; Perlinger, J. A.; Appl. Catal., B 2002, 37, 139.

64. Ghauch, A.; Chemosphere 2001, 43, 1109.

65. Sayles, G. D.; You, G.; Wang, M.; Kupferle, M. J.; Environ. Sci. Technol. 1997, 31, 3448

66. Weber, E. J.; Adams, R. L.; Environ. Sci. Technol. 1995, 29, 1163.

67. Ghauch, A.; Rima J.; Amine, C.; Martin-Bouyer, M.; Chemosphere 1999, 39, 1309.

68. Klausen, J.; Ranke J.; Schwarzenbach, R. P.; Chemosphere 2001, 44, 511.

69. Devlin, J. F.; Klausen, J.; Schwarzenbach, R. P.; Environ. Sci. Technol. 1998, 32, 1941.

70. Choe, S.; Chang, Y. Y.; Hwang, K. Y.; Khim, J.; Chemosphere 2000, 41, 1307.

71. Muftikian, F. C. R.; Fernando, Q.; Korte, N.; Chemosphere 1997, 35, 2689.

72. Doong, R.; Chang, W.; J. Photochem. Photobiol., A 1998, 116, 221.

73. Bell, L. S.; Devlin, J. F.; Gillham, R. W.; Binning, P. J.; Contam. Hydrol. 2003, 66, 201

74. Mu, Y.; Yu, W. Q.; Zheng, J. C.; Zhang, S. J.; Sheng, G. P.; Chemosphere 2004, 74, 789

75. Westerhoff, P.; James, J.; Water Res. 2003, 37, 1818.

76. Larson, R. A.; Weber, E. J.; Reaction Mechanisms in Environmental Organic Chemistry, CRC Press: Boca Raton, 1994.

77. Cao, J.; Wei, L.; Huang, Q.; Wang, L.; Chemosphere 1998, 38, 565.

78. Nam, S.; Tratnyek, P. G.; Water Res. 2000, 34, 1837.

79. Roy, G.; Donato, P.; Görner, T.; Barres, O.; Water Res. 2003, 37, 4954.

80. Oturan, M. A.; J. Appl. Electrochem. 2000, 30, 475.

81. Liao, C. H.; Kang, S. F.; Hsu, Y. W.; Water Res. 2003, 37, 4109.

82. Bergendahl, J. A.; Thies, T. P.; Water Res. 2004, 38, 327.

83. Deng, N.; Luo, F.; Wu, F.; Xiao, M.; Water Res. 2000, 34, 2408.

84. Oh, S.; Chiu, P. C.; Kim, B. J.; Cha, D. K.; Water Res. 2003, 37, 4275.

85. Schmelling, D. C.; Gray, K. A.; Kamat, P. V.; Environ. Sci. Technol. 1996, 30, 2547.

86. Huang, C. P.; Dong C.; Tang, Z.; Waste. Manage 1993, 13, 361. 